\section{TRICHOVIRIDIN AND DERMADIN FROM TRICHODERMA SP. TK-1}

\section{Atsushi Tamura, Hirotada Kotani and Shunsuke NARUto}

Research \& Development Division, Dainippon Pharmaceutical Co., Ltd., Suita, Osaka, Japan

(Received for publication October 2, 1974)

During the course of our studies on new antibiotics, we found that Trichoderma sp. Tk-1 produced substances A and B which showed inhibitory activities against both Staphylococcus aureus and Escherichia coli. From their chemical and physical properties, substances A and B were identified as trichoviridin $^{13}$ and dermadin ${ }^{2)}$, respectively. The strain Tk-1 was obtained from a soil sample and classified in the Trichoderma koningiigroup according to RIFAI ${ }^{3)}$. This paper presents some characteristics of the strain, the isolation of substances $\mathrm{A}$ and $\mathrm{B}$, and the approach to the structure elucidation of trichoviridin.

Characteristics of the strain Tk-1 are as follows.

Morphology: Conidiophores and their branches long and slender, $10 \sim 40 \mu$ in diameter, without sterile hyphal elongation. Side branches formed in false verticils. Phialides rather slender and not crowded, nine pinshaped, $7 \sim 15 \mu$, disposed regularly in false whorls. Phialospores ellipsoidal, $3.2 \sim 4.0 \times$ $2.4 \sim 3.2 \mu$, smooth-walled. Globose or ellipsoidal chlamydospores, $8 \sim 9 \times 12 \sim 13 \mu$, produced on substrate mycelium.

Colony: Growth rapid. Aerial hyphae floccose, white or pale yellow (phialospores poor) on malt extract agar, peptone-glucose agar, CZAPEK agar, SABouraud agar, synthetic mucor agar, yeast-starch agar and sugar-yeast agar.

Reverse side of colony: Pale yellow on above mentioned media.

Soluble pigment: None or trace (pale yellow) in above-mentioned media.

According to the classification system proposed by RIFAI ${ }^{3)}$, the strain Tk-1 may be classified into the section Aa-D-E (Trichoderma koningii-group, i.e. T. koningii, T. aureoviride and T. harzianum), but named species in this section are different from the strain Tk-1 in the following properties. Phialospores of $T$. koningii are mostly elliptic-subcylindrical. Colonies of $T$. aureoviride grow very slowly on malt extract agar. Phialospores of $T$. harzianum are mostly globose or subglobose. However, in other properties, including morphological and cultural properties, the strain Tk-1 shows good agreement with these species. On the other hand, $T$. viride is distinguished from this strain in the surface of phialospores, namely the former is rough-walled, but the latter smooth-walled. Therefore, the strain Tk-1 was classified as a strain of $T$. koningiigroup.

The fungi were shake-cultured at $30^{\circ} \mathrm{C}$ for 2 days in a medium consisting of $2 \%$ glucose, $1 \%$ defatted soybean meal, $0.2 \% \mathrm{NaCl}$ and $0.05 \% \mathrm{CaCO}_{3} \quad(\mathrm{pH} 6.2)$. The cultured broth was freed from mycelium and extracted with ethyl acetate. The ethyl acetate extract was evaporated to dryness and the residue was purified by chromatography on a column of silica gel (developing solvent: $\mathrm{CHCl}_{3}$ ). The active fractions were concentrated to small volume and cooled. From 6 liters of cultured broth, $390 \mathrm{mg}$ of crude crystals (substance A) was isolated. The crystals were further purified by direct recrystallization from chloroform. The aqueous layer was concentrated to dryness, and purified by chromatography on columns of Sephadex LH $20(\mathrm{MeOH})$ and silica gel $\left(\mathrm{CHCl}_{3}\right)$. The active fractions were concentrated to small volume and cooled. From 6 liters of cultured broth, $20 \mathrm{mg}$ of substance B, m.p. $<85^{\circ} \mathrm{C}$, was isolated. Its IR and UV spectra were superimposable on those of dermadin ${ }^{2)}$. Therefore, substance B was identified as dermadin.

$$
\begin{array}{ll}
\mathrm{UV}: & \lambda_{\max }^{\mathrm{EtOH}} 220 \mathrm{~nm}\left(\mathrm{E}_{1 \mathrm{~cm}}^{1 \%} 84.6\right) \\
\mathrm{IR}(\mathrm{KBr}): & 3100 \sim 2850,2120,1685,1430,1410, \\
& 1325,975,945,840,800 \mathrm{~cm}^{-1} .
\end{array}
$$

The identification of substance A with trichoviridin ${ }^{1)}$ was accomplished in the following manner. Substance A, m.p. $93 \sim 95^{\circ} \mathrm{C}$, $[\alpha]_{\mathrm{D}}^{25}-36.8^{\circ}(c 0.5, \mathrm{MeOH})$, had the molecular formula $\mathrm{C}_{8} \mathrm{H}_{8} \mathrm{NO}_{4}$ (Anal. Calcd.: C, 52.46; $\mathrm{H}$, 4.95; N, 7.65; Found: C, 52.31; H, 4.89; N, 7.65). Its IR spectrum was superimposable on that of trichoviridin ${ }^{1}$. However, its structure was not discussed earlier. 
Fig. 1. NMR spectra of substance $\mathrm{A}\left(60 \mathrm{MHz}\right.$, in $\mathrm{CDCl}_{3}$ and $\left.\mathrm{CDCl}_{3}+\mathrm{D}_{2} \mathrm{O}\right)$.

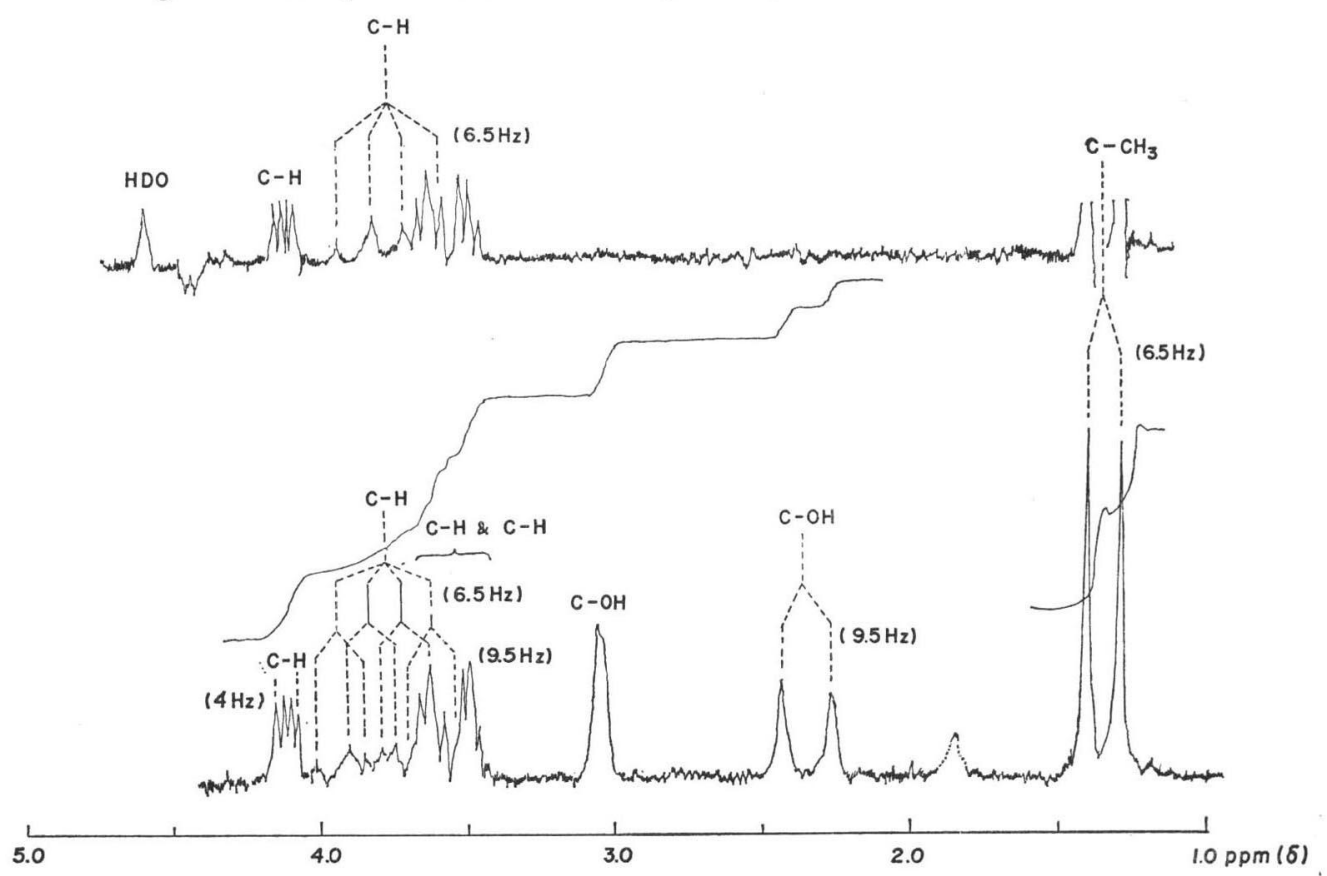

$\mathrm{UV}: \quad \lambda_{\max }^{\mathrm{EtOHI}} 215 \mathrm{~nm}\left(\mathrm{E}_{1 \mathrm{~cm}}^{1 \%}\right.$ sh, 17.5)

IR $(\mathrm{KBr})$ : $3530,3340,2150,1405,1183,1085$, $1008,890 \mathrm{~cm}^{-1}$.

The molecular weight was unable to determine by mass spectrometry.

Trichoviridin exhibited a nitrile band at $2150 \mathrm{~cm}^{-1}$ in its IR spectrum and showed a positive hydroxylamine ferric chloride test ${ }^{4}$. On acidic treatment, trichoviridin decomposed to give some carbonyl compounds (IR : $\nu_{\mathrm{C}=0}$ $1730 \mathrm{~cm}^{-1}$ ) in which the nitrile bands had disappeared. These observations suggest the presence of a cyanhydrin function

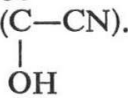

The NMR spectra shown in Fig. 1 indicates the following partial structures:<smiles>CC(O)C(C)(C)C</smiles><smiles>COC(C)C(C)OC</smiles><smiles>CC(C)(C)C(O)C#N</smiles>

(ABX type)

Considering with the molecular formula, these partial structures include all of the elements of trichoviridin.

Substances A and B showed inhibitory activities against $S$. aureus and $E$. coli, but both substances were very unstable on exposure to air.

\section{Acknowledgements}

The authors express deep thanks to Dr. H. Nonomura, Faculty of Engineering, Yamanashi University, for his kind guidance and valuable advice, and to Director Dr. H. Takamatsu, Dr. H. Nishimura and Dr. K. Yokogawa, Research and Development Division, Dainippon Pharmaceutical Co., Ltd., for their encouragement throughout this work. Thanks are also due to the members of the Analytical Center of our Research Laboratories for micro-analyses and spectroscopic measurements.

\section{References}

1) Yamano, T.; T. Henmi, K. Yamamoto \& $K$. TsUBAKI: Production procedure of antibiotic. Japan Patent 45-15,435, May 29, 1970

2) Coats, J.H.; C. E. Meyer \& T.R. Pyke: Antibiotic dermadin and a process for producing the same. U.S. Patent 3,627,882, Dec. 14, 1971

3) Rifai, M. A.: A revision of the genus Trichoderma. Mycological Papers No. 116: 1 56, 1969

4) Soloway, S. \& A. Lipschitz: Colorimetric test for amides and nitriles. Anal. Chem. 24: 898 900, 1952 